\title{
Holmium laser enucleation of the prostate: patient selection and perspectives
}

This article was published in the following Dove Press journal:

Research and Reports in Urology

21 October 2016

Number of times this article has been viewed

\section{Tracy Marien Mustafa Kadihasanoglu \\ Nicole L Miller}

Department of Urology, Vanderbilt Medical Center, Nashville, TN, USA
Correspondence: Nicole L Miller Department of Urologic Surgery, Vanderbilt Medical Center, A-I302 MCN, Nashville, TN 37273 , USA

$\mathrm{Tel}+\mathrm{I} 6153223807$

Fax + I 6153228990

Email nicole.miller@vanderbilt.edu
Background: Multiple endoscopic surgical options exist to treat benign prostatic hyperplasia (BPH), including holmium laser enucleation of the prostate (HoLEP). HoLEP alleviates obstructive prostatic tissue via enucleation, both bluntly with a resectoscope and by cutting tissue with the holmium laser, and removal of adenoma via morcellation. This article reviews patient selection for HoLEP in order to optimize outcomes, costs, and patient satisfaction.

Methods: A literature review of all studies on HoLEP was conducted. Studies that focused on outcomes in regard to patient and procedural factors were closely reviewed and discussed.

Results: Various studies found that men with large or small prostates, on antithrombotic therapy, in urinary retention, with bladder hypocontractility, with prostate cancer, undergoing retreatment for BPH, or in need of concomitant surgery for bladder stones and other pathologies do well with HoLEP, as demonstrated by excellent functional and symptomatic outcomes as well as low complication rates. There is a $74-78 \%$ rate of retrograde ejaculation following HoLEP. Techniques to preserve ejaculatory function following enucleative techniques have not been able to demonstrate a significant improvement.

Conclusion: Patient selection for HoLEP can include most men with bothersome BPH who have evidence of bladder outlet obstruction and are healthy enough to undergo surgery. The ability to safely perform concomitant surgery with HoLEP benefits the patient by sparing them an additional anesthetic and also decreases costs. Patients should be made aware of the risk of retrograde ejaculation following HoLEP and counseled on treatment alternatives if maintaining ejaculatory function is desired. Keywords: holmium laser nucleation of the prostate, HoLEP, benign prostatic hyperplasia, prostate size, urinary retention, patient selection

\section{Introduction}

Benign prostatic hyperplasia (BPH) is a medical condition of older men. Clinical manifestations range from asymptomatic to debilitating lower urinary tract symptoms (LUTS), urinary retention, and renal insufficiency. Many endoscopic surgical procedures exist to treat BPH. These procedures remove obstructive prostatic tissue via resection, vaporization, ablation, enucleation with morcellation, incision, and retraction of obstructive lateral lobe tissue. Patient and procedural factors make patient selection imperative to achieve optimal outcome, decrease the risk of complications, reduce medical expenditure, and achieve patient satisfaction.

Holmium laser enucleation of the prostate (HoLEP) is a surgical intervention that removes obstructive BPH tissue via enucleation and morcellation. Many studies have demonstrated the superiority of HoLEP to resect greater amounts of tissue compared 
to transurethral resection of the prostate (TURP) and photovaporization of the prostate (PVP). ${ }^{1,2}$ Long-term data are emerging that this enucleative procedure has durable results with a low rate of retreatment. ${ }^{3,4}$ In order to achieve optimal outcomes for the surgical management of BPH, proper patient selection is important. Factors such as prostate size, anticoagulation and/or antiplatelet therapy, detrusor hypocontractility, urinary retention, surgical retreatment of $\mathrm{BPH}$, bladder calculi, the need for concurrent surgical procedures, and patient desire to maintain ejaculatory function may affect surgical outcome, cost, and patient satisfaction with treatment. The aim of this review was to discuss patient selection for HoLEP.

\section{Methods}

A comprehensive review using the search engine PubMed, which accesses the MEDline database, was conducted on HoLEP and other BPH procedures when necessary from 1998 through June 2016. Specifically, studies assessing outcomes in regard to prostate size, configuration, use of perioperative antithrombotic medications, detrusor function, urinary retention, surgical retreatment of BPH, bladder calculi, concurrent surgery, and ejaculatory function were carefully reviewed. Details of some of the studies that were reviewed are summarized in tables.

\section{Results HoLEP technique}

HoLEP is an endoscopic surgical procedure that uses a combination of blunt dissection with the resectoscope and cutting with the holmium laser to develop the plane between the prostatic adenoma and the surgical capsule. This enucleation of essentially the transition zone of the prostate closely approximates open simple prostatectomy. By defocusing the laser, the holmium laser is capable of achieving coagulation as well as providing excellent hemostasis. Typically, a 100-120 $\mathrm{W}$ laser is used with laser settings varying from 2 to $2.5 \mathrm{~J}$ and 20 to $50 \mathrm{~Hz}$. Lower energy settings are used near more critical structures such as the external urethral sphincter to decrease the potential for injury. Typically, a $550 \mu$ end-firing holmium laser fiber is used, which is also effective at treating bladder stones.

Briefly, in terms of surgical technique, first a thorough cystoscopy is performed to identify the veru montanum (a marker for the external urethral sphincter) and bilateral ureteral orifices. The prostatic adenoma can be enucleated using a two-lobe technique or a three-lobe technique depending on whether there is a large median lobe. When performing enucleation using a two-lobe technique, an incision is made at the 60 'clock position and carried down to the depth of the capsule. The urothelium at the prostatic apex is incised with the laser under one of the lateral lobes, and the end of the resectoscope is preferentially used to bluntly dissect the tissue plane between the adenoma and the peripheral zone of the prostate. The apical dissection is carried circumferentially toward the 12 o'clock position, developing the lateral enucleation plane. The resectoscope is brought back between the two lateral lobes, and an incision is made from the bladder neck to the apex at the 12 o'clock position, separating the lateral lobes at the anterior commissure. The anterior enucleation plane is developed and then joined with the posterior enucleation plane. Once the majority of the lateral lobe is free, on low energy settings, the resectoscope is rotated from the 12 o'clock position to the 6 o'clock position around the lobe and the remaining bridge of mucosa at the apex is divided. The remaining attachments mostly at the bladder neck and floor of the prostate are then released, and the lobe is detached and pushed into the bladder. The contralateral prostatic lobe is enucleated in a similar fashion.

When performing HoLEP using the three-lobe technique, which is often preferred when there is a large median lobe, the initial incisions are made at approximately the 5 o'clock (between the median lobe and the patient's left lateral lobe) and 7 o'clock (between the median lobe and the patient's right lateral lobe) positions. Similar to the 6 o'clock incision described previously, these are both taken down to the depth of the capsule and just proximal to the veru montanum. Next, the mucosal bridge between these two grooves at the apex is incised. The posterior plane of the median lobe is then developed both with blunt enucleation using the beak of the resectoscope and incision with the laser. The remaining bladder neck attachments are divided, and the lobe is released into the bladder. The remaining lateral lobes are then taken in a similar fashion using the two-lobe approach described earlier.

Once hemostasis is achieved, morcellation is performed using a nephroscope with a bridge that connects to the outer sheath of the resectoscope. The bladder must be distended to avoid morcellator injury. This is achieved by running an inflow port through the resectoscope sheath and a second one through the nephroscope. Fluid is evacuated from the bladder with the morcellator, which engages tissue through suction. Once all tissue is removed and hemostasis is achieved, a three-way Foley catheter is typically placed and continuous bladder irrigation (CBI) is started when necessary. A voiding trial is conducted the next morning and the patient is discharged home on the first postoperative day.

\section{Prostate size}

The size and shape of the prostate gland are important to consider when selecting surgical treatment for BPH. The current American Urological Association (AUA) guidelines regarding 
the management of BPH note that emerging evidence suggests a significant role for transurethral enucleation as a surgical option for men with very large prostates $(>100 \mathrm{~g}) .{ }^{5}$ The European Association of Urology guidelines recommend HoLEP or open simple prostatectomy as first-line therapy for prostates $>80$ g. ${ }^{6}$ Simple prostatectomy is generally reserved for large prostates, given the increased invasiveness of the procedure and the fact that smaller prostates can be approached with several other less invasive options. Large prostates (>80 g) are not amenable to some endoscopic treatments, given the limited ability to remove large amounts of tissue in a single setting. The configuration of BPH is important, and some procedures such as prostatic urethral lift (PUL) and transurethral incision of the prostate (TUIP) are ineffective when treating men with large median lobes.

Conversely, the outcomes of HoLEP have been shown to be independent of prostate size and shape (Table 1). ${ }^{7-14}$ Wisenbaugh et al compared outcomes of HoLEP in men with trilobar (ie, with a median lobe) and bilobar prostate morphology, and found similar outcomes with a greater decrease in postopera- tive postvoid residual (PVR) in the trilobar group. ${ }^{15}$ Seki et al compared 97 patients undergoing HoLEP and divided them into three groups: those with prostates $<50 \mathrm{~g}$ (59 men), $\geq 50$ $\mathrm{g}$ but less than $100 \mathrm{~g}$ (27 men), and $\geq 100 \mathrm{~g}$ (11 men). ${ }^{12}$ As expected, men with large prostates had longer operative times and more tissue enucleated. Postoperatively, there was no difference in regard to bleeding, urinary tract infection (UTI), bladder neck contracture (BNC), urinary incontinence, urinary flow rate, PVR, or symptom score. Shah et al compared 354 patients by prostate size stratified as $<60 \mathrm{~g}$ (235 men), 60-100 $\mathrm{g}$ (77 men), and >100 g (42 men). ${ }^{10}$ Similarly, at 1-year followup, there was no difference in urinary flow, PVR, or symptom score between the three groups of men. There was also no difference in the rate of postoperative BNC, UTI, cystoscopy with clot evacuation, or need for blood transfusion. However, men in this cohort with prostate size $>100 \mathrm{~g}$ did have a higher rate of meatal/submeatal stenosis $(7.1 \%$ vs $1.3 \%-2.6 \%)$ and urethral stricture $(4.8 \%$ vs $1.3 \%-2.6 \%)$.

Matlaga et al reported on their experience with HoLEP on glands $>125 \mathrm{~g}$ (mean $170 \mathrm{~g}$, range $125-309 \mathrm{~g}$ ) in 86 men. ${ }^{13}$

Table I HoLEP outcomes based on prostate size

\begin{tabular}{|c|c|c|c|}
\hline Study & Prostate size $(\mathbf{N})$ & Efficacy & Complications \\
\hline Lee et $\mathrm{al}^{7}$ & $\begin{array}{l}<40 \mathrm{~g}(15) \\
40-80 \mathrm{~g}(15) \\
>80 \mathrm{~g}(15)\end{array}$ & $\begin{array}{l}\text { - No differences between HoLEP vs TURP } \\
\text { - Outcomes of HoLEP stratified by prostate } \\
\text { size not compared }\end{array}$ & $\begin{array}{l}\text { - No difference in TUl for HoLEP vs TURP } \\
\text { - Outcomes of HoLEP stratified by prostate size } \\
\text { not compared }\end{array}$ \\
\hline Krambeck et $\mathrm{al}^{8}$ & $>175 \mathrm{~g}(57)$ & $\begin{array}{l}\text { - Significant improvement at } 6 \text { months FU } \\
\text { - AUASS } 6.5 \text { from } 19.0 \text { preop } \\
\text { - Qmax } 18.6 \mathrm{~mL} / \mathrm{s} \text { from } 8.2 \mathrm{~mL} / \mathrm{s} \text { preop }\end{array}$ & $\begin{array}{l}\text { - Blood transfusion (2), clot evacuation (I) } \\
\text { - No one with persistent incontinence }\end{array}$ \\
\hline Humphreys et al ${ }^{9}$ & $\begin{array}{l}<75 g(164) \\
75-125 g(226) \\
>125 g(117)\end{array}$ & $\begin{array}{l}\text { - Similar postop catheterization, AUASS, } \\
\text { Qmax, and PSA }\end{array}$ & $\begin{array}{l}\text { - Similar complication rates between the three } \\
\text { groups }\end{array}$ \\
\hline Shah et $\mathrm{al}^{10}$ & $\begin{array}{l}<60 \mathrm{~g}(235) \\
60-100 \mathrm{~g}(77) \\
>100 \mathrm{~g}(42)\end{array}$ & - No difference at I-y FU & $\begin{array}{l}\text { - 仓 Meatal stenosis }(7.1 \text { vs } 1.3 \%-2.6 \%) \text { if }>100 \mathrm{~g} \\
\text { - 仓 Urethral stricture }(4.8 \text { vs } 1.3 \%-2.6 \%) \text { if }>100 \mathrm{~g}\end{array}$ \\
\hline Kuntz et al ${ }^{11,14}$ & $\begin{array}{l}>100 \mathrm{~g} \\
(60-\text { in initial study, } \\
42-5-y \mathrm{FU})\end{array}$ & $\begin{array}{l}\text { - Compared to open SPP (60 per arm) } \\
\text { - Similar resected tissue ( } 94 \text { vs } 96 \text { g) } \\
\text { - HoLEP had shorter LOS, less blood loss, } \\
\text { shorter catheterization time, but longer } \\
\text { operative time (I35 vs } 90 \text { min) } \\
\text { 5-y FU } \\
\text { - No difference vs open SPP at 5-y FU } \\
\text { - AUASS } 3.0 \text { from } 22.1 \text { preop } \\
\text { - Qmax } 24.3 \mathrm{~mL} / \mathrm{s} \text { from } 3.8 \mathrm{~mL} / \mathrm{s} \text { preop } \\
\text { - PVR } 10.6 \mathrm{~mL} \text { from } 280 \mathrm{~mL}\end{array}$ & $\begin{array}{l}\text { - I3\% open SPP required blood transfusion vs } 0 \% \\
\text { in the HoLEP arm }(P=0.003) \\
\text { - Three in each arm required cystoscopy and } \\
\text { fulguration postop } \\
\text { 5-y FU } \\
\text { - No difference vs open SPP } \\
\text { - Urethral stricture (2), BNC (I) }\end{array}$ \\
\hline Seki et al' ${ }^{12}$ & $\begin{array}{l}<50 \mathrm{~g}(59) \\
\geq 50-99 \mathrm{~g}(27) \\
\geq 100 \mathrm{~g}(\mathrm{II})\end{array}$ & - No difference at 6 months FU & - No difference \\
\hline Matlaga et al ${ }^{13}$ & $>125 \mathrm{~g}(86)$ & $\begin{array}{l}\text { - Significant improvement at } 12 \text { months FU } \\
\text { - AUASS } 5.1 \text { from } 19.6 \text { preop } \\
\text { - Qmax } 24.9 \mathrm{~mL} / \mathrm{s} \text { from } 9.1 \mathrm{~mL} / \mathrm{s} \text { preop }\end{array}$ & $\begin{array}{l}\text { - Sepsis (I), clot evacuation (I), blood transfusion } \\
\text { (I), myocardial infarction (I) } \\
\text { - Long-term postop complications not discussed }\end{array}$ \\
\hline
\end{tabular}

Note: The numbers in parentheses are the number of patients in the series who experienced the complication.

Abbreviations: N, number; FU, follow-up; AUASS, AUA symptom score; Qmax, peak urinary flow rate; preop, preoperatively; postop, postoperatively; SPP, simple suprapubic prostatectomy; y, year; TUI, transient urinary incontinence; PVR, postvoid residual; PSA, prostate-specific antigen; HoLEP, holmium laser enucleation of the prostate; TURP, transurethral resection of the prostate; LOS, length of stay; BNC, bladder neck contracture; min, minutes. 
There was no comparison group in this series. At 12 months follow-up, these men had significant improvement in AUA symptom score (AUASS) (5.1 from 19.6) and peak urinary flow rate $(24.9 \mathrm{~mL} / \mathrm{s}$ from $9.1 \mathrm{~mL} / \mathrm{s})$. There were few immediate/perioperative complications - one patient with a history of recurrent UTIs developed sepsis; one experienced clot retention on the same day of surgery requiring a return to the operating room for evacuation, this same patient also required a blood transfusion; and one patient had a myocardial infarction. Long-term complications such as urethral stricture, BNC, and incontinence were not discussed. This same group later reported their experience with HoLEP in 57 men with prostates $>175 \mathrm{~g}$ (mean $218 \mathrm{~g}$, range 175-391 g). ${ }^{8}$ The mean enucleated tissue weight was $176 \mathrm{~g}$ (range 48-532 g). One patient required take back for clot evacuation and two required blood transfusions. At 6 months follow-up, AUASS had improved to 6.5 from 19.0, and peak urinary flow rate was $18.6 \mathrm{~mL} / \mathrm{s}$ from $8.2 \mathrm{~mL} / \mathrm{s}$. No patient had persistent urinary incontinence. Other long-term complications including urethral stricture and BNC were not discussed.

Lee et al compared the outcomes of TURP and HoLEP for all prostate sizes, stratified as $<40 \mathrm{~g}, 40-80 \mathrm{~g}$, and $>80 \mathrm{~g}^{7}$ There were 45 men who underwent TURP and 45 who underwent HoLEP, 15 for each size category. The two larger prostate groups had significantly more tissue removed with HoLEP than TURP. The $<40 \mathrm{~g}$ prostate groups had a similar amount of tissue resected (6.3 vs $8.7 \mathrm{~g}$ ). Operating time was longer for the HoLEP cohort in men with prostates $<40 \mathrm{~g}$ (84 vs 52 minutes, $P=0.040$ ) and those with prostates $40-80 \mathrm{~g}$ (123 vs 89 minutes, $P=0.048$ ) but was similar for men with prostates $>80 \mathrm{~g}$. A higher rate of transient incontinence was noted in the TURP group ( $18 \%$ vs $9 \%, P=0.178$ ), though this was not statistically significant. Long-term complications were not reviewed. HoLEP in this series had similar efficacy and safety as TURP for small prostates.

Another group also stratified patients undergoing HoLEP into three groups based on prostate size, though overall the prostate size was larger with 164 men having prostates $<75$ g, 226 men with prostates 75-125 g, and 117 men with prostates $>125 \mathrm{~g} .{ }^{9}$ There was no difference in intraoperative complications or postoperative complications. One patient with a prostate $>125 \mathrm{~g}$ did require a second-stage procedure. There was significant improvement in maximum urinary flow rate and AUASS for groups with no differences between the three groups postoperatively.

Kuntz et al randomized 120 men with prostates $>100$ $\mathrm{g}$ to HoLEP or open simple suprapubic prostatectomy (SPP). ${ }^{11,14}$ The resected amount of prostatic tissue was similar between both the groups (93.7 vs $96.4 \mathrm{~g}, P=0.9$ ). Men undergoing HoLEP had a shorter hospital course (69.6 vs 251.0 hours, $P<0.0001$ ), less blood loss (hemoglobin loss of 1.9 vs $2.8 \mathrm{~g} / \mathrm{dL}, P<0.0001$ ), catheterization time (30.8 vs 194.4 hours, $P<0.0001$ ), but longer operative times (135.9 vs 90.6 minutes, $P<0.0001$ ) (Table 1 ). No patient in the HoLEP arm required blood transfusions, though $13 \%$ of men who underwent simple prostatectomy required transfusions $(P=0.003)$. Forty-two men in the HoLEP arm and 32 in the SPP cohort completed 5-year follow-up. Excellent functional outcomes were similar between the two groups. The rate of urethral stricture and $\mathrm{BNC}$ were similar between the two groups. Given the equivalent outcomes and low complication rates, HoLEP was deemed a true endourological alternative to SPP.

These series demonstrate that HoLEP is a safe and effective surgical treatment option for men with small and large prostates of any configuration. TURP and PVP are also appropriate for small prostates, and in some cases may be faster compared to HoLEP. Furthermore, HoLEP provides a minimally invasive option for men with very large prostates. While both open as well as laparoscopic/robotic SPP are feasible options to surgically treat men with large prostates, these procedures are more invasive, require longer indwelling catheter time, and are associated with increased rates of postoperative pain and convalescence. ${ }^{11}$ Conversely, HoLEP has been shown to be effective in men with very large prostates with an average postoperative catheterization time of only 18.5 hours (range 6-96 hours). ${ }^{8}$ With similar outcomes but faster recovery secondary to its minimally invasive nature, HoLEP is not just an alternative to SPP but a superior treatment approach.

\section{Antithrombotic medications}

The use of antithrombotic therapy including anticoagulation medications (ACs) (ie, warfarin, dabigatran, enoxaparin, and heparin) and antiplatelet medication (AP) agents (ie, aspirin, clopidogrel, and dipyridamole/aspirin) in the perioperative period is a known risk factor for increased bleeding complications with all types of surgical procedures. In some cases, these medications cannot be bridged or held due to the risk of thrombotic and embolic complications. Several series have reported on the superiority of laser enucleation and vaporization procedures over TURP to treat $\mathrm{BPH}$ with regard to risk of bleeding complications. ${ }^{2,16-18}$ One series of 116 men undergoing PVP who continued oral aspirin, warfarin, or clopidogrel through surgery, given the risk of thromboembolic events, found no need for perioperative blood transfusions with similar decrease in postoperative hemoglobin compared to 
Table 2 Antithrombotic agents and HoLEP

\begin{tabular}{|c|c|c|c|c|}
\hline Study & $\mathbf{N}$ & $\begin{array}{l}\text { Control } \\
\text { group }\end{array}$ & Study characteristics & Outcomes \\
\hline El Tayeb et $\mathrm{al}^{20}$ & 116 & $\mathrm{I}, 558$ & $\begin{array}{l}\text { - } 30 \text { continued antithrombotics ( } 1 \text { dipyridamole/ } \\
\text { aspirin, } 9 \text { aspirin } 325 \mathrm{mg}, 10 \text { clopidogrel, I5 warfarin, } \\
3 \text { dabigatran, } 2 \text { enoxaparin) } \\
\text { - } 86 \text { held antithrombotics perioperatively } \\
\text { ( I dipyridamole/aspirin, } 39 \text { aspirin } 325 \mathrm{mg} \text {, } \\
36 \text { clopidogrel, } 35 \text { warfarin, } 2 \text { dabigatran) }\end{array}$ & 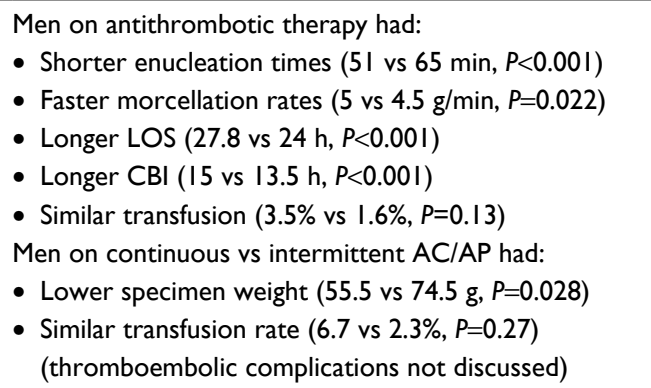 \\
\hline Bishop et $\mathrm{al}^{21}$ & 52 & 73 & $\begin{array}{l}\text { - Antithrombotics taken through HoLEP: } 3 \\
\text { dipyridamole/aspirin, } 16 \text { clopidogrel, } 22 \text { warfarin } \\
\text { - Men on antithrombotics were significantly older } \\
(75.1 \text { vs } 71.7 \text { y, } P=0.02 \text { ) and had a higher ASA score } \\
(3 \text { vs } 2, P<0.0001)\end{array}$ & $\begin{array}{l}\text { Antithrombotic arm had: } \\
\text { - A longer LOS ( } 2 \text { vs I d, } P=0.014) \\
\text { - Higher transfusion rate }(7.7 \text { vs } 0 \%, P=0.028) \\
\text { No thromboembolic complications in either group }\end{array}$ \\
\hline $\begin{array}{l}\text { Tyson and } \\
\text { Lerner }\end{array}$ & 39 & 37 & $\begin{array}{l}\text { - I3 warfarin (mean INR I.5), } 25 \text { aspirin, I clopidogrel } \\
\text { continued through surgery }\end{array}$ & $\begin{array}{l}\text { - Significant intraoperative hematuria obscuring vision } \\
\text { resulting in staged procedure occurred in } 5 \text { controls } \\
\text { and } 2 \text { on antithrombotics }(P=0.34) \\
\text { - No patient required a blood transfusion }\end{array}$ \\
\hline Elzayat et $\mathrm{al}^{23}$ & 83 & None & $\begin{array}{l}\text { - } 14 \text { antithrombotics continued through HoLEP } \\
\text { - } 34 \text { on LMWH substitution through HoLEP } \\
\text { - } 33 \text { held antithrombotics prior to HoLEP } \\
\text { - } 2 \text { men with hemophilia }\end{array}$ & $\begin{array}{l}\text { Blood transfusion rate: } \\
\text { - } 2(14.2 \%) \text { on continued antithrombotic therapy } \\
\text { - } 5(14.7 \%) \text { on LMWH through HoLEP } \\
\text { - One patient on clopidogrel required Plavix } ® \\
\text { (clopidogrel bisulfate) intraop and staged morcellation }\end{array}$ \\
\hline
\end{tabular}

Abbreviations: $\mathrm{N}$, number; LOS, length of stay; CBI, continuous bladder irrigation; LMWH, low-molecular-weight heparin; HoLEP, holmium laser enucleation of the prostate; $y$, years; d, days; min, minutes; h, hours; AC/AP, anticoagulation and antiplatelet medication; cont, continous; intraop, intraoperatively.

controls. ${ }^{19}$ Several studies have specifically looked at HoLEP and the perioperative use of AC/AP therapy (Table 2). ${ }^{20-23}$

Specifically, one recent large series compared 116 patients who required AC/AP therapy undergoing HoLEP with 1,558 HoLEP patients who were not on AC/AP therapy. ${ }^{20}$ Patients were taking aspirin $325 \mathrm{mg}$, clopidogrel, dipyridamole/aspirin, dabigatran, enoxaparin, or warfarin. Men on aspirin $81 \mathrm{mg}$ were placed in the control arm. El Tayeb et al reported that men on antithrombotic therapy had similar preoperative characteristics and perioperatively had shorter enucleation times, faster morcellation rates, slightly longer length of stay by 2.8 hours, and slightly longer time on CBI by 1.5 hours. There was no difference in the need for blood transfusions (1.6\% vs 3.5\%), and postoperative PVR and AUASS were similar at 6 months follow-up. This group also compared the 30 men who were on continuous AC/AP through HoLEP to 86 men whose medications were held in the perioperative period - typically one week prior to and one week following HoLEP. The only difference between these two groups was that slightly more tissue was enucleated in the intermittent AC/AP therapy arm ( 74.5 vs $55.5 \mathrm{~g}, P=0.028$ ). There was a $6.7 \%$ transfusion rate in the continuous AC/AP arm versus $2.3 \%$ in the intermittent group, and this difference was not statistically significant.
Another series retrospectively reviewed 125 consecutive patients who underwent HoLEP and compared the 52 on antithrombotic therapy at the time of surgery to the 73 who were not. ${ }^{21}$ The 73 men in this series not on antithrombotic therapy included those naïve to these medications, and those deemed low risk for thromboembolism and whose antithrombotic medications were held or bridged with heparin in the perioperative period. The other 52 men who continued antithrombotic therapy through HoLEP given the high risk of a thromboembolic complication included 11 on aspirin, 3 on dipyridamole/aspirin, 16 on clopidogrel, and 22 on warfarin (mean INR of 2.6). Those staying on antithrombotic therapy were significantly older (75.1 vs 71.7 years, $P=0.02$ ) and had higher ASA scores ( 3 vs $2, P<0.0001)$ than those in the control arm. Those on antithrombotics also had a longer length of stay ( 2 vs 1 day, $P=0.014$ ) and were more likely to receive a blood transfusion $(7.7 \%$ vs $0 \%, P=0.028)$. One patient on dipyridamole/aspirin, one on clopidogrel, and two on coumadin required blood transfusions. All patients received two units of blood except for one patient on warfarin with an INR of 3.9 who received four. None of these patients required reoperation. There were no thromboembolic events. The authors of this article deemed HoLEP safe in patients 
on $\mathrm{AC} / \mathrm{AP}$ medications despite the slightly higher surgical risk profile.

Another series retrospectively reviewed 39 patients on antithrombotics (13 on warfarin with a mean INR of 1.5 at the time of surgery, 24 on aspirin, and 1 on clopidogrel) in the perioperative HoLEP period compared to 37 controls. $^{22}$ Five patients in the control arm and two patients in the antithrombotic arm had significant intraoperative hematuria $(P=0.34)$ that required early termination of the procedure and a second stage to complete HoLEP. No patient required blood transfusions in this series. However, most patients on warfarin (all but two) had subtherapeutic INRs and the aspirin dosage was not mentioned. If most of these patients were on a baby aspirin and most were subtherapeutic on warfarin, then this cohort may not represent a group truly on antithrombotic therapy at the time of HoLEP.

One of the first series looking at antithrombotics and HoLEP retrospectively reviewed 81 men on anticoagulant or antiplatelet therapy without a control arm and two men with hemophilia. ${ }^{23}$ Fourteen patients continued antithrombotics through HoLEP, 34 were on low-molecular-weight heparin substitution, and 33 held antithrombotics prior to surgery. HoLEP was successfully performed in all patients. One patient who continued clopidogrel through HoLEP required intraoperative platelet transfusion and seven others required blood transfusions (mean 3.7 units, ranging 2-7 units per patient). Three patients returned to the operating room for cystoscopy and fulguration. There were no thromboembolic complications reported, though one patient had a myocardial infarction requiring management in the intensive care unit for 5 days.

Overall, most of these studies only had a small number of patients continuing AC/AP medication through HoLEP. Thus far, with this limited data, HoLEP appears safe and effective in men with BPH who take antithrombotic medications in the perioperative period. There is a trend toward lower risk of blood transfusion when these medications can be safely held or bridged in the perioperative period. While performing HoLEP can be more challenging on AC/AP medications, the excellent hemostatic properties of the holmium laser make this approach feasible. Better studies are needed to confirm these preliminary results, and inexperienced surgeons should use caution when attempting HoLEP on fully anticoagulated men.

\section{Urinary retention}

Urinary retention is the primary indication for surgery in up to $42 \%$ of men with BPH. ${ }^{24}$ Some series have found a higher rate of postoperative urinary retention, bleeding complications, need for reoperation, and cardiopulmonary complications for those undergoing open SPP for urinary retention versus LUTS. ${ }^{24}$ Additionally, those in urinary retention were noted to have a higher 30-day mortality rate. Another series comparing men undergoing TURP for retention versus other indications noted a threefold higher risk of infection in the retention cohort. ${ }^{25}$

Two series have specifically studied the outcomes of men in urinary retention undergoing treatment with HoLEP (Table 3). ${ }^{26,27}$ Peterson et al reported on their experience with 164 men undergoing HoLEP for urinary retention. ${ }^{27}$ Following HoLEP, all patients were voiding spontaneously and no major complications were reported. A more contemporary series compared the outcomes of 95 patients in urinary retention to 136 men who were voiding spontaneously prior to HoLEP. ${ }^{26}$ Perioperatively, men in urinary retention were less likely to require a blood transfusion $(1.0 \%$ vs $4.4 \%, P=0.01)$. No patient in preoperative urinary retention required longterm recatheterization postoperatively. Both groups, men who were voiding spontaneously and those in urinary retention preoperatively, had significant improvement in AUASS without any statistically significant differences at long-term follow-up. Peak urinary flow was higher for men

Table 3 Outcomes of men in urinary retention and HoLEP

\begin{tabular}{|c|c|c|c|c|c|}
\hline Study & $\begin{array}{l}\text { Comparison } \\
\text { group }\end{array}$ & $\mathbf{N}$ & $\begin{array}{l}\text { Postop number } \\
\text { voiding } \\
\text { spontaneously (\%) }\end{array}$ & Efficacy & Complications \\
\hline Johnsen et $\mathrm{al}^{26}$ & Yes $(N=136)$ & 95 & $95(100)$ & $\begin{array}{l}\text { - All Qmax }>18 \mathrm{~mL} / \mathrm{s} \\
\text { - All PVR }<60 \mathrm{~mL} \\
\text { - No difference between the two } \\
\text { groups }\end{array}$ & $\begin{array}{l}\text { - No difference in postop } \\
\text { complications between the } \\
\text { two groups }\end{array}$ \\
\hline Peterson et $\mathrm{a}^{27}$ & No & 165 & $165(100)$ & $\begin{array}{l}\text { - At } 6 \text { months FU Qmax } 26.7 \mathrm{~mL} / \mathrm{s} \\
\text { - PVR } 32.5 \mathrm{~mL} \\
\text { - AUASS } 5\end{array}$ & $\begin{array}{l}\text { - At } 6 \text { months FU, } 5 \text { patients } \\
\text { using pads for incontinence }\end{array}$ \\
\hline
\end{tabular}

Abbreviations: Qmax, peak urinary flow; PVR, postvoid residual; postop, postoperative; FU, follow-up; AUASS, AUA symptom score; HoLEP, holmium laser enucleation of the prostate; AUA, American Urological Association. 
not in urinary retention at 6 and 12 months follow-up and similar to men not in urinary retention at longer follow-up. PVRs at follow-up were all $<60 \mathrm{~mL}$ and similar between the two groups. The complication rate was low and similar between both the groups. HoLEP is an excellent option for men in urinary retention, given the $100 \%$ rate of spontaneous voiding postoperatively and similar complication rate to men who were not in retention prior to HoLEP.

\section{Non-neurogenic impaired bladder contractility}

Some men with urinary retention may also have detrusor hypocontractility or acontractility. These patients in urinary retention with urodynamic evidence of poor bladder function are often managed with long-term catheterization rather than surgery, given the concern that they will remain in retention despite treating any obstruction at the bladder outlet. However, one group theorized that substantial deobstruction with HoLEP may result in spontaneous urination, normal cycling of the bladder, rehabilitation of the detrusor muscle, and recovery of contractility. They studied 14 men with detrusor hypocontractility and 19 men with acontractility as demonstrated on urodynamics with evidence of bladder outlet obstruction from BPH. ${ }^{28}$ All of these men were catheter dependent. Following HoLEP, all 14 men with bladder hypocontractility and 18/19 (95\%) with acontractility were able to void spontaneously. Four men with acontractility were voiding with Valsalva effort only, and the other 14 had return of bladder contractility as noted on urodynamics. At 6 months follow-up, the hypocontractile cohort was voiding with an average peak urinary flow of $21 \mathrm{~mL} / \mathrm{s}$, PVR of $53 \mathrm{~mL}$, and AUASS of 3 . The men in the acontractile group were voiding with an average peak urinary flow of $17 \mathrm{~mL} / \mathrm{s}$, PVR of $107 \mathrm{~mL}$, and AUASS of 4. As demonstrated by this series, HoLEP is an excellent option for the treatment of men with cystoscopic evidence of obstructive BPH and poor bladder function.

\section{Prostate cancer}

"Channel" TURP, where resection of the prostate is purposely not carried out toward the capsule, is an accepted outlet procedure for men who have locally advanced and metastatic prostate cancer with urinary retention or LUTS. About 9.3\% of men with prostate cancer undergo TURP for palliation or for multimodal therapy prior to external beam radiation..$^{29}$ However, channel TURP is overall associated with worse functional outcomes, treatment failure, and urinary incontinence. ${ }^{30,31}$ The use of active surveillance (AS) for low-risk prostate cancer has increased, with $40 \%-49 \%$ of men electing conservative management in recent studies. ${ }^{32,33}$ Many men have concurrent $\mathrm{BPH}$ and prostate cancer, with $6 \%-13 \%$ incidentally found to have prostate cancer at the time of TURP or HoLEP. ${ }^{34-36}$

One series studied HoLEP in 62 men with prostate cancer in the setting of palliation $(n=19)$, in preparation for radiation therapy $(\mathrm{n}=22)$, and in men on $\operatorname{AS}(n=21) .{ }^{37}$ Men on palliation or undergoing radiation therapy as expected had higher Gleason scores. The men undergoing HoLEP for palliation of obstruction due to prostate cancer had slower enucleation times ( 0.6 vs 0.7 and $0.9 \mathrm{~g} / \mathrm{min}, P=0.01$ ), likely secondary to extension of local disease and difficulty identifying anatomic planes, higher postoperative AUASS (9.8 vs 5.9 and $3.9, P=0.047$ ), and lower rate of being pad free postoperatively $(31.6 \%$ vs $59.1 \%$ and $85.7 \%, P=0.033)$. Men in the AS arm had the most favorable outcomes in terms of enucleation time, AUASS, and need for pads postoperatively. Prostate cancer was noted in the specimen in two-third of men on palliation and less than half of those with plans to undergo radiation therapy or on $\mathrm{AS}(P=0.041)$. One patient required a blood transfusion postoperatively and three developed clot urinary retention that was successfully managed with bladder irrigation. About $90 \%$ of patients were voiding spontaneously postoperatively, and $17 \%$ had some degree of urinary incontinence. One patient developed a urethral stricture and two developed BNC - one of these patients had undergone radiation therapy. There was no difference in complication rates between the three groups. No patient required reoperation for persistent LUTS from residual or regrowth of prostatic tissue.

Studies evaluating TURP in men with prostate cancer had similar findings in that men with prostate cancer following TURP had higher AUASS. ${ }^{31}$ Marszalek et al reported an 11\% rate of incontinence in men undergoing palliative TURP in their series, though the current cohort was older compared to the HoLEP series discussed earlier. ${ }^{30}$ A couple advantages of palliative TURP over palliative HoLEP include the ability to resect ureteral orifice if the prostate cancer is invading the bladder and the ability to resect without needing to find the anatomic planes at the apex, which is not possible in some cases of local invasion into the external sphincter. Overall, HoLEP is safe and effective in relieving obstruction in men with prostate cancer, particularly in these patients with low risk disease on AS.

\section{Surgical retreatment of $\mathrm{BPH}$}

The need for surgical retreatment for regrowth of BPH following TURP and PVP occurs at a rate of 5\%-17.7\% at 5-year 
Table 4 HoLEP for the surgical retreatment of BPH

\begin{tabular}{|c|c|c|c|c|}
\hline Study & rHoLEP & HoLEP & Efficacy & Complications \\
\hline Marien et $\mathrm{al}^{41}$ & 360 & $\mathrm{I}, 882$ & $\begin{array}{l}\text { Men undergoing rHoLEP had: } \\
\text { - Shorter OR time, } 86 \text { vs } 9 \mathrm{I} \text { minutes, } P=0.003 \\
\text { - Less EBL, } 36 \text { vs } 80 \mathrm{~mL}, P=0.000 \mathrm{I} \\
\text { - Shorter LOS, I.I vs I.3 d, } P=0.0 \text { I } \\
\text { - Less tissue removed, } 69 \text { vs } 76 \mathrm{~g}, P=0.023 \\
\text { - Similar Qmax and PVR postop } \\
\text { - Significantly improved postop AUASS but } \\
\text { slightly higher than primary, } 6.5 \text { vs } 5.0 \text {, } \\
P<0.000 \text { I }\end{array}$ & $\begin{array}{l}\text { - Similar rate of postop UTI and BNC } \\
\text { - Similar rate of new incontinence } \\
\text { - Higher rate of clot retention for rHoLEP, } 4.7 \% \text { vs } \\
\text { I. } 8 \%, P=0.0 \text { I } \\
\text { - Higher rate of urethral stricture for rHoLEP, } 3.3 \% \\
\text { vs } 1.5 \%, P=0.43\end{array}$ \\
\hline $\begin{array}{l}\text { Jaeger and } \\
\text { Krambeck }^{42}\end{array}$ & 37 & 74 & $\begin{array}{l}\text { Similar enucleation and morcellation rates, } \\
\text { tissue weight resected, catheterization time, } \\
\text { and LOS } \\
\text { Qmax and PVR improved and similar } \\
\text { - AUASS improved and slightly lower in the } \\
\text { HoLEP arm, } 7.52 \text { vs } 5.21, P=0.0060\end{array}$ & $\begin{array}{l}\text { - No patient required a blood transfusion } \\
\text { - There were similar and low rates of SUI ( } 6 \% \text { vs } 8 \%) \text {, } \\
\text { BNC ( } 3 \% \text { vs } 0 \%) \text {, urethral stricture ( } 0 \% \text { vs I } \%) \text {, } \\
\text { hematuria }(0 \% \text { vs } 1 \%) \text {, and UTI ( } 0 \% \text { vs } 1 \% \text { ) for } \\
\text { rHoLEP and HoLEP, respectively }\end{array}$ \\
\hline Elshal et $\mathrm{al}^{43}$ & 76 & 978 & $\begin{array}{l}\text { Men undergoing rHoLEP had: } \\
\text { - Shorter enucleation time, } 76 \text { vs } 92 \text { minutes, } P=0.29 \\
\text { - Similar morcellation time, } 16.9 \text { vs } 16.6 \text { minutes, } P=\text { ns } \\
\text { - Less tissue resected, } 52.6 \text { vs } 64.5 \mathrm{~g}, P=0.03 \\
\text { - Similar LOS, I. } 2 \text { vs } 1.3 \mathrm{~d}, P=0.79 \\
\text { - At I-year FU similar Qmax ( } 23.4 \text { vs } 25.9 \mathrm{~mL} / \mathrm{s}) \text {, } \\
\text { PVR ( } 32.5 \text { vs } 24.1 \mathrm{~mL}) \text {, and AUASS }(4.5 \text { vs } 4.4)\end{array}$ & $\begin{array}{l}\text { - Similar rates of clot evacuation and infection } \\
\text { - No men undergoing rHoLEP required blood } \\
\text { transfusions } \\
\text { - Similar rates of SUl at I-year FU ( } 5 \text { after HoLEP and } \\
\text { I in rHoLEP arm), P>0.05 } \\
\text { - Similar rates of BNC and urethral stricture }\end{array}$ \\
\hline
\end{tabular}

Note: The numbers in parentheses are the number of patients in the series who experienced the complication.

Abbreviations: rHoLEP, retreatment HoLEP; HoLEP, holmium laser enucleation of the prostate; OR, operating room; EBL, estimated blood loss; d, days; Qmax, peak urinary flow rate; PVR, postvoid residual; UTI, urinary tract infection, BNC, bladder neck contracture, AUASS, AUA symptoms score; SUI, stress urinary incontinence; LOS, length of stay; BPH, benign prostatic hyperplasia; postop, postoperative; FU, follow-up; ns, not significant.

follow-up. ${ }^{38-40}$ Several series have sought to assess the outcomes of men undergoing surgery for BPH regrowth with retreatment holmium laser enucleation of the prostate (rHoLEP) (Table 4).

Most recently, Marien et al compared 360 men who underwent retreatment of BPH following prior BPH surgery to 1,882 men undergoing primary HoLEP ${ }^{41}$ They found that men in the retreatment arm actually had shorter operation times ( 86 vs 91 minutes, $P=0.003$ ), lower blood loss (36 vs $80 \mathrm{~mL}, P=0.0001$ ), shorter length of stay (1.1 vs 1.3 days, $P=0.01$ ), and not surprisingly less tissue resected ( $69 \mathrm{vs} 76 \mathrm{~g}$, $P=0.023$ ). Postoperatively, both groups had similar and significant improvement in urinary flow rates (maximum urinary flow from 9.0 to 26.7 vs from 10.3 to $24.4 \mathrm{~mL} / \mathrm{s}, P=0.12$ ) and PVR (from 281 to 50 vs from 204 to $58 \mathrm{~mL}, P=0.44$ ). AUASS was significantly improved from preoperative evaluation (20.4 and 20.5) for primary HoLEP versus retreatment, respectively, though postoperatively the AUASS was slightly better for those who underwent primary treatment ( $5.0 \mathrm{vs} 6.5$, $P<0.0001)$. There was a similar rate of postoperative UTI (3.9\% vs $5.3 \%, P=0.23)$, BNC ( $0.8 \%$ vs $1.7 \%, P=0.28)$, and urinary incontinence $(3.7 \%$ vs $2.1 \%, P=0.26)$ between the two groups. There was a slightly higher rate of postoperative clot retention ( $4.7 \%$ vs $1.8 \%, P=0.01)$ and urethral stricture $(3.3 \%$ vs $1.5 \%, P=0.43)$ in the rHoLEP arm.

Jaeger and Krambeck evaluated the safety and outcomes of rHoLEP in 37 men compared to 74 men matched according to preoperative transrectal ultrasound prostate size undergoing primary HoLEP. ${ }^{42}$ They reported similar enucleation and morcellation time between the two groups. Both groups had significant and similar improvement in urinary flow and PVR. In contrast to the prior study, AUASS improvement was slightly better in the retreatment arm (5.21 vs 7.52, $P=0.0060$ ). There was no difference in the rate of postoperative stress urinary incontinence (SUI), BNC, urethral stricture, postoperative hematuria, or UTI (Table 4).

Elshal et al was the first group to specifically report on their experience with HoLEP in the retreatment setting in 2012. ${ }^{43}$ They found that the plane of enucleation was identified without extra difficulty in men who had undergone prior BPH surgery, though there was trend for more energy per gram of prostate tissue required for enucleation (226.7 vs $186.4 \mathrm{~kJ}, P=0.08$ ). Men undergoing retreatment actually had short enucleation times, similar morcellation times, less tissue resected (as expected), and similar length of hospital stay. At 1-year follow-up, the two groups of men had similar maximum urinary flows, PVRs, and AUASS (Table 4). There were similar low rates of postoperative complications including long-term SUI, BNC, and urethral stricture.

All of these series demonstrated that rHoLEP is not only technically feasible but also safe and provides overall similar and excellent outcomes compared to men who undergo primary treatment. Additionally, given the low retreatment 
rate for $\mathrm{BPH}$ regrowth following $\operatorname{HoLEP}(0 \%-1.4 \%)$, patients may be best served by undergoing this procedure primarily. ${ }^{3,4}$

\section{Bladder stones}

The presence of bladder calculi secondary to BPH and bladder outlet obstruction is an absolute indication for a bladder outlet procedure. ${ }^{5}$ While cystolitholapaxy can be safely performed at the time of all endoscopic BPH surgeries including TURP and PVP, HoLEP has the advantage of using the same instrument that is used to remove prostatic adenoma. The holmium laser is a multimodality laser that is excellent for cutting tissue, obtaining hemostasis, and fragmenting stones. Several series have reported their experience with HoLEP and concurrent bladder calculi treatment (Table 5).

One recent series compared 25 men undergoing HoLEP with concurrent holmium laser cystolitholapaxy (HLC) and 206 men undergoing HoLEP only. ${ }^{44}$ Cystolitholapaxy was always performed first. There was no need to stage any procedure. As expected, men undergoing concurrent HLC had slightly longer operative times (178 vs 157 minutes, $P=0.042$ ). The estimated blood loss and amount of tissue enucleated were similar between both the groups. Postoperatively, men in both groups had similar AUASS and urinary flows. However, men undergoing HLC had significantly lower PVRs postoperatively ( 29 vs $55 \mathrm{~mL}, P=0.0094$ ). There were ten complications, and they were all in the HoLEP-only cohort (four BNCs, three urethral strictures, two patients requiring cystoscopy and clot evacuation, and one with SUI).

Another series reviewed their outcomes with 32 men undergoing HoLEP and concurrent HLC. ${ }^{45}$ Similar to the prior study reviewed, HoLEP and HLC were technically feasible in all patients who were rendered stone free postoperatively. No patients required blood transfusions. No patient had persistent SUI. One patient developed a urethral stricture, one UTI, and one meatal stenosis. Both series illustrated that HoLEP with HLC is feasible and safe. It is also cost-effective as the same laser is used to treat both the prostate and the stones.

\section{Other concomitant surgeries}

Older men with symptomatic BPH often have concomitant pathology sometimes related to bladder outlet obstruction (bladder diverticula) and sometimes unrelated (bladder tumors and nephrolithiasis, etc). Aside from HLC, others have shared their experience with HoLEP and other simultaneous procedures including ureteral stent placement, ureteroscopy, bladder diverticulectomy, and hernia repair. Patel et al compared 334 men who underwent HoLEP alone to 38 men who underwent HoLEP and concomitant surgery (Table 6) ${ }^{46}$ They categorized procedures into simple (likely to have little impact on ability to perform HoLEP), intermediate (potential for bleeding that could impair visualization and ability to perform HoLEP), or complex (procedures requiring bladder reconstruction). There was no difference in outcomes for those in the simple and intermediate procedure groups. In the complex procedure group, there was a longer operative time, higher estimated blood loss, longer time with an indwelling catheter, and longer length of stay (Table 5). Indeed, the longer catheterization time was expected in this group, given all patients underwent bladder reconstruction. There were no intraoperative complications or readmissions. One patient in the intermediate arm had a myocardial infarction postoperatively.

Shah et al described their experience with HoLEP and simultaneous laparoscopic extraperitoneal diverticulectomy in three patients. ${ }^{47}$ The mean operative time was 63 minutes for the HoLEP portion of the procedure and 246 minutes for the diverticulectomy (Table 5). There were no major intraoperative or postoperative complications. Voiding parameters and symptom scores had improved for all patients postoperatively, with an impressive improvement in PVR from 997 to $164 \mathrm{~mL}$.

Table 5 Outcomes of HoLEP and cystolitholapaxy

\begin{tabular}{|c|c|c|c|c|}
\hline Study & $\begin{array}{l}\text { HoLEP + } \\
\text { HLC }\end{array}$ & $\begin{array}{l}\text { HoLEP } \\
\text { only }\end{array}$ & Efficacy & Complications \\
\hline Marien et $\mathrm{al}^{44}$ & 25 & 206 & $\begin{array}{l}\text { - All procedures completed in one stage } \\
\text { - Slightly longer OR time for HLC (I } 78 \text { vs } 157 \text { minutes, } \\
P=0.042) \\
\text { - Similar AUASS, Qmax, and lower PVR ( } 29 \text { vs } 55 \mathrm{~mL} \text {, } \\
P=0.0094) \text { for concurrent HLC }\end{array}$ & $\begin{array}{l}\text { - No complications in the HLC } \\
\text { arm }\end{array}$ \\
\hline Shah et $\mathrm{al}^{45}$ & 32 & $\mathrm{n} / \mathrm{a}$ & $\begin{array}{l}\text { - All procedures completed in one stage } \\
\text { - Significant improvement in AUASS, Qmax, and PVR } \\
\text { postoperatively }(P<0.00 \mathrm{I})\end{array}$ & $\begin{array}{l}\text { - No blood transfusions or clot } \\
\text { retention } \\
\text { - No persistent SUI }\end{array}$ \\
\hline
\end{tabular}

Abbreviations: HLC, holmium laser cystolitholapaxy; OR, operating room; Qmax, peak urinary flow rate; PVR, postvoid residual; AUASS, AUA symptom score; SUI, stress urinary incontinence; HoLEP, holmium laser enucleation of the prostate; n/a, not applicable. 
Table 6 Outcomes of HoLEP and other concomitant surgeries

\begin{tabular}{|c|c|c|c|c|}
\hline Study & HoLEP + CS & $\begin{array}{l}\text { HoLEP } \\
\text { only }\end{array}$ & Concomitant surgical procedures & Outcomes \\
\hline Patel et al ${ }^{46}$ & 38 & 334 & $\begin{array}{l}\text { - Simple: stent removal (I), stent placement } \\
\text { (I), meatotomy (3), umbilical hernia repair } \\
\text { (3), URS (I), spermatocelectomy (I), } \\
\text { hydrocelectomy (I), inguinal hernia repair } \\
\text { (I), removal of prostatic urethral stent (I) } \\
\text { - Intermediate: cystolitholapaxy (I6), } \\
\text { open cystolithotomy (I), TURBT (3), } \\
\text { circumcision/TURBT (I) } \\
\text { - Complex: bladder diverticulectomy/left } \\
\text { distal ureterectomy/reimplant (I), bladder } \\
\text { diverticulectomy/urachal mass (I), robotic } \\
\text { bladder diverticulectomy (2) }\end{array}$ & $\begin{array}{l}\text { - No difference compared to simple or } \\
\text { intermediate procedures } \\
\text { - If complex procedure, significantly longer } \\
\text { OR time ( } 22 \text { I vs } 65 \text { minutes, } P=0.007) \text {, higher } \\
\text { EBL ( } 92 \text { vs } 33 \mathrm{~mL}, P=0.0 \text { I } 2 \text { ), longer } \\
\text { catheter time ( } 8.5 \text { vs I d, } P=0.04 \mathrm{I}) \text {, and } \\
\text { longer LOS ( } 2 \text { vs I d, } P=0.032) \\
\text { - No complications except an } \mathrm{Ml} \text { in the } \\
\text { intermediate group } \\
\text { - Significant improvement in Qmax, PVR, } \\
\text { and symptom score }\end{array}$ \\
\hline Shah et $\mathrm{al}^{47}$ & 3 & $\mathrm{n} / \mathrm{a}$ & $\begin{array}{l}\text { - Laparoscopic extraperitoneal } \\
\text { diverticulectomy (3) }\end{array}$ & $\begin{array}{l}\text { - No major complications } \\
\text { - No blood transfusions } \\
\text { - Improvement in Qmax, PVR, symptom } \\
\text { scores for all }\end{array}$ \\
\hline Kim et $\mathrm{al}^{48}$ & 11 & $\mathrm{n} / \mathrm{a}$ & $\begin{array}{l}\text { - URS (8) } \\
\text { - } \text { PCNL (2) } \\
\text { - URS and PCNL (I) }\end{array}$ & $\begin{array}{l}\text { - No short- or long-term complications } \\
\text { - No transfusions } \\
\text { - All with FU imaging stone free } \\
\text { - Improvement in Qmax, PVR, and } \\
\text { symptom scores postop }\end{array}$ \\
\hline
\end{tabular}

Abbreviations: HoLEP, holmium laser enucleation of the prostate; CS, concomitant surgery; URS, ureteroscopy; TURBT, transurethral resection of bladder tumor; OR, operating room; EBL, estimated blood loss; d, days; MI, myocardial infarction; Qmax, peak urinary flow rate; PVR, postvoid residual; PCNL, percutaneous nephrolithotomy, FU, follow-up; postop, postoperative; LOS, length of stay; n/a, not applicable.

Another series specifically examined their results with men undergoing HoLEP with concomitant upper tract surgery for nephrolithiasis. ${ }^{48}$ Eight of these patients underwent ureteroscopy, two underwent percutaneous nephrolithotomy (PCNL), and one patient underwent ureteroscopy and PCNL at the time of HoLEP. HoLEP was always performed first and stone surgery second. The AUASS improved from 21.8 to 6.3 following HoLEP after an average of $118 \mathrm{~g}$ of prostatic tissue was removed. The mean length of stay was 1.4 days. All seven patients with follow-up imaging were stone free. No patient required a blood transfusion, and there were no short- or long-term complications.

As these series demonstrate, in addition to cystolitholapaxy, many other procedures can be safely performed at the time of HoLEP. From less invasive procedures such as ureteral stent placement and ureteroscopy to more invasive surgeries including PCNL and diverticulectomy, patients did well when performed at the same time as HoLEP. Concomitant surgery with HoLEP spares the patient an additional anesthetic for another procedure without compromising improvement in voiding function and symptom score or increasing the risk of complications.

\section{Retrograde ejaculation}

Retrograde ejaculation is a common complication of prostate surgery occurring in $74 \%-78 \%$ of men undergoing
HoLEP. ${ }^{17,49-51}$ Rates of retrograde ejaculation are similar to those reported for TURP, though significantly higher than men undergoing TUIP $(0 \%-35 \%)^{52-54}$ and men undergoing PUL, which early published series suggest preserves antegrade ejaculation. ${ }^{55-59}$ One study aimed to improve the rate of retrograde ejaculation following HoLEP by sparing the ejaculatory hood, defined as the paracollicular and supracollicular tissue $>1 \mathrm{~cm}$ proximal to the veru montanum. ${ }^{60}$ This ejaculatory hood sparing technique has been shown to work for TURP ${ }^{61}$ and laser vaporization of the prostate, with a $92 \%$ rate of antegrade ejaculation preservation. ${ }^{62}$

In the series by Kim et al, the ejaculatory hood sparing technique was employed in 26 men and standard HoLEP in 26 other men. ${ }^{60}$ Ejaculation was preserved in $46.2 \%$ of those undergoing the hood sparing technique and $26.9 \%$ of those undergoing standard HoLEP, with a $P$-value of 0.249 . These authors theorize that this technique was less effective at preserving ejaculatory function compared to its use in those undergoing TURP and laser vaporization of the prostate, given the complete removal of apical tissue with HoLEP. They speculate that for maintenance of antegrade ejaculation with HoLEP, some apical tissue would have to be preserved. This information should be made available to the patient preoperatively to allow sound shared decision making prior to HoLEP. 


\section{Conclusion}

Nearly all men with symptomatic BPH are candidates for surgical management with HoLEP. HoLEP is effective and safe for all prostate sizes, in the setting of urinary retention, non-neurogenic impaired bladder contractility, and when retreatment is necessary. Studies to date of HoLEP in the setting of antithrombotic medications are overall small, though results are encouraging. Furthermore, though no cost-analysis studies are available for review, intuitively, HoLEP is costeffective for those who require concomitant surgery including for bladder calculi where the same holmium laser fiber is used as well as for those who need other concurrent urologic and nonurologic procedures. Patients should be made aware of the risk of retrograde ejaculation following HoLEP. Overall, patient selection for HoLEP is broad.

\section{Disclosure}

The authors report no conflicts of interest in this work.

\section{References}

1. Moody JA, Lingeman JE. Holmium laser enucleation for prostate adenoma greater than $100 \mathrm{gm}$. : comparison to open prostatectomy. J Urol. 2001;165(2):459-462.

2. Tan AH, Gilling PJ, Kennett KM, Frampton C, Westenberg AM, Fraundorfer MR. A randomized trial comparing holmium laser enucleation of the prostate with transurethral resection of the prostate for the treatment of bladder outlet obstruction secondary to benign prostatic hyperplasia in large glands (40 to 200 grams). J Urol. 2003;170(4 Pt 1):1270-1274

3. Gilling PJ, Wilson LC, King CJ, Westenberg AM, Frampton CM, Fraundorfer MR. Long-term results of a randomized trial comparing holmium laser enucleation of the prostate and transurethral resection of the prostate: results at 7 years. BJU Int. 2012;109(3):408-411.

4. Gilling PJ, Aho TF, Frampton CM, King CJ, Fraundorfer MR. Holmium laser enucleation of the prostate: results at 6 years. Eur Urol. 2008;53(4):744-749.

5. McVary KT, Roehrborn CG, Avins AL, et al. Update on AUA guideline on the management of benign prostatic hyperplasia. $J$ Urol. 2011;185(5):1793-1803

6. Oelke M, Bachmann A, Descazeaud A, et al. EAU guidelines on the treatment and follow-up of non-neurogenic male lower urinary tract symptoms including benign prostatic obstruction. Eur Urol. 2013;64(1):118-140.

7. Lee MH, Yang HJ, Kim DS, Lee CH, Jeon YS. Holmium laser enucleation of the prostate is effective in the treatment of symptomatic benign prostatic hyperplasia of any size including a small prostate. Korean $J$ Urol. 2014;55(11):737-741.

8. Krambeck AE, Handa SE, Lingeman JE. Holmium laser enucleation of the prostate for prostates larger than 175 grams. J Endourol. 2010;24(3):433-437.

9. Humphreys MR, Miller NL, Handa SE, Terry C, Munch LC, Lingeman JE. Holmium laser enucleation of the prostate - outcomes independent of prostate size? J Urol. 2008;180(6):2431-2435; discussion 2435.

10. Shah HN, Sodha HS, Kharodawala SJ, Khandkar AA, Hegde SS, Bansal MB. Influence of prostate size on the outcome of holmium laser enucleation of the prostate. BJU Int. 2008;101(12):1536-1541.

11. Kuntz RM, Lehrich K, Ahyai SA. Holmium laser enucleation of the prostate versus open prostatectomy for prostates greater than 100 grams: 5-year follow-up results of a randomised clinical trial. Eur Urol. 2008;53(1):160-166.

12. Seki N, Tatsugami K, Naito S. Holmium laser enucleation of the prostate: comparison of outcomes according to prostate size in 97 Japanese patients. J Endourol. 2007;21(2):192-196.
13. Matlaga BR, Kim SC, Kuo RL, Watkins SL, Lingeman JE. Holmium laser enucleation of the prostate for prostates of $>125 \mathrm{~mL}$. BJU Int. 2006;97(1):81-84.

14. Kuntz RM, Lehrich K, Ahyai S. Transurethral holmium laser enucleation of the prostate compared with transvesical open prostatectomy: 18-month follow-up of a randomized trial. J Endourol. 2004;18(2):189-191.

15. Wisenbaugh ES, Nunez-Nateras R, Mmeje CO, Warner JN, Humphreys MR. Does prostate morphology affect outcomes after holmium laser enucleation? Urology. 2013;81(4):844-848.

16. Li S, Zeng XT, Ruan XL, et al. Holmium laser enucleation versus transurethral resection in patients with benign prostate hyperplasia: an updated systematic review with meta-analysis and trial sequential analysis. PLoS One. 2014;9(7):e101615

17. Kuntz RM, Ahyai S, Lehrich K, Fayad A. Transurethral holmium laser enucleation of the prostate versus transurethral electrocautery resection of the prostate: a randomized prospective trial in 200 patients. $J$ Urol. 2004;172(3):1012-1016.

18. Zhou Y, Xue B, Mohammad NA, et al. Greenlight high-performance system (HPS) 120-W laser vaporization versus transurethral resection of the prostate for the treatment of benign prostatic hyperplasia: a meta-analysis of the published results of randomized controlled trials. Lasers Med Sci. 2016;31(3):485-495.

19. Ruszat R, Wyler S, Forster T, et al. Safety and effectiveness of photoselective vaporization of the prostate (PVP) in patients on ongoing oral anticoagulation. Eur Urol. 2007;51(4):1031-1038; discussion 1038-1041.

20. El Tayeb MM, Jacob JM, Bhojani N, Bammerlin E, Lingeman JE. Holmium laser enucleation of the prostate in patients requiring anticoagulation. J Endourol. 2016;30(7):805-809.

21. Bishop CV, Liddell H, Ischia J, et al. Holmium laser enucleation of the prostate: comparison of immediate postoperative outcomes in patients with and without antithrombotic therapy. Curr Urol. 2013;7(1):28-33.

22. Tyson MD, Lerner LB. Safety of holmium laser enucleation of the prostate in anticoagulated patients. J Endourol. 2009;23(8):1343-1346.

23. Elzayat E, Habib E, Elhilali M. Holmium laser enucleation of the prostate in patients on anticoagulant therapy or with bleeding disorders. J Urol. 2006;175(4):1428-1432.

24. Pickard R, Emberton M, Neal DE. The management of men with acute urinary retention. National Prostatectomy Audit Steering Group. $\mathrm{Br}$ J Urol. 1998;81(5):712-720.

25. Mebust WK, Holtgrewe HL, Cockett AT, Peters PC. Transurethral prostatectomy: immediate and postoperative complications. a cooperative study of 13 participating institutions evaluating 3,885 patients. 1989 . J Urol. 2002;167(2 Pt 2):999-1003; discussion 1004.

26. Johnsen NV, Kammann TJ, Marien T, Pickens RB, Miller NL. Comparison of holmium laser prostate enucleation outcomes in patients with or without preoperative urinary retention. J Urol. 2016;195(4 Pt 1):1021-1026.

27. Peterson MD, Matlaga BR, Kim SC, et al. Holmium laser enucleation of the prostate for men with urinary retention. J Urol. 2005;174(3):9981001; discussion 1001.

28. Mitchell CR, Mynderse LA, Lightner DJ, Husmann DA, Krambeck AE. Efficacy of holmium laser enucleation of the prostate in patients with non-neurogenic impaired bladder contractility: results of a prospective trial. Urology. 2014;83(2):428-432.

29. Krupski TL, Stukenborg GJ, Moon K, Theodorescu D. The relationship of palliative transurethral resection of the prostate with disease progression in patients with prostate cancer. BJU Int. 2010;106(10):1477-1483.

30. Marszalek M, Ponholzer A, Rauchenwald M, Madersbacher S. Palliative transurethral resection of the prostate: functional outcome and impact on survival. BJU Int. 2007;99(1):56-59.

31. Crain DS, Amling CL, Kane CJ. Palliative transurethral prostate resection for bladder outlet obstruction in patients with locally advanced prostate cancer. J Urol. 2004;171(2 Pt 1):668-671.

32. Womble PR, Montie JE, Ye Z, et al. Contemporary use of initial active surveillance among men in Michigan with low-risk prostate cancer. Eur Urol. 2015;67(1):44-50. 
33. Cooperberg MR, Carroll PR. Trends in management for patients with localized prostate cancer, 1990-2013. JAMA. 2015;314(1):80-82.

34. Bhojani N, Boris RS, Monn MF, Mandeville JA, Lingeman JE. Coexisting prostate cancer found at the time of holmium laser enucleation of the prostate for benign prostatic hyperplasia: predicting its presence and grade in analyzed tissue. $J$ Endourol. 2015;29(1):41-46.

35. Mai KT, Isotalo PA, Green J, Perkins DG, Morash C, Collins JP. Incidental prostatic adenocarcinomas and putative premalignant lesions in TURP specimens collected before and after the introduction of prostrate-specific antigen screening. Arch Pathol Lab Med. 2000;124(10):1454-1456.

36. Rivera ME, Frank I, Viers BR, Rangel LJ, Krambeck AE. Holmium laser enucleation of the prostate and perioperative diagnosis of prostate cancer: an outcomes analysis. J Endourol. 2014;28(6):699-703.

37. Becker A, Placke A, Kluth L, et al. Holmium laser enucleation of the prostate is safe in patients with prostate cancer and lower urinary tract symptoms - a retrospective feasibility study. $J$ Endourol. 2014;28(3): 335-341.

38. Wasson JH, Bubolz TA, Lu-Yao GL, Walker-Corkery E, Hammond CS, Barry MJ. Transurethral resection of the prostate among medicare beneficiaries: 1984 to 1997. For the Patient Outcomes Research Team for Prostatic Diseases. J Urol. 2000;164(4):1212-1215.

39. Madersbacher S, Lackner J, Brossner C, et al. Reoperation, myocardial infarction and mortality after transurethral and open prostatectomy: a nation-wide, long-term analysis of 23,123 cases. Eur Urol. 2005;47(4):499-504.

40. Malde S, Rajagopalan A, Patel N, Simoes A, Choi W, Shrotri N. Potassium-titanyl-phosphate laser photoselective vaporization for benign prostatic hyperplasia: 5-year follow-up from a district general hospital. J Endourol. 2012;26(7):878-883.

41. Marien T, Kadihasanoglu M, Tangpaitoon T, et al. Outcomes of HoLEP performed in the retreatment setting. AUA 2016; May 8, 2016; San Diego, CA. Abstract: MP42-08.

42. Jaeger CD, Krambeck AE. Holmium laser enucleation of the prostate for persistent lower urinary tract symptoms after prior benign prostatic hyperplasia surgery. Urology. 2013;81(5):1025-1029.

43. Elshal AM, Elmansy HM, Elhilali MM. Feasibility of holmium laser enucleation of the prostate (HoLEP) for recurrent/residual benign prostatic hyperplasia (BPH). BJU Int. 2012;110(11 Pt C):E845-E850.

44. Marien TP, Tumen A, Mitchell C, Miller NL. Does cystolitholapaxy at the time of holmium laser enucleation of the prostate affect outcomes? Abstract presented at World Congress of Endourology 2015; October 3, 2015; London, England.

45. Shah HN, Hegde SS, Shah JN, Mahajan AP, Bansal MB. Simultaneous transurethral cystolithotripsy with holmium laser enucleation of the prostate: a prospective feasibility study and review of literature. $B J U$ Int. 2007;99(3):595-600.

46. Patel A, Nunez R, Mmeje CO, Humphreys MR. Safety and feasibility of concomitant surgery during holmium laser enucleation of the prostate (HoLEP). World J Urol. 2014;32(6):1543-1549.

47. Shah HN, Shah RH, Hegde SS, Shah JN, Bansal MB. Sequential holmium laser enucleation of the prostate and laparoscopic extraperitoneal bladder diverticulectomy: initial experience and review of literature. J Endourol. 2006;20(5):346-350.
48. Kim SC, Tinmouth WW, Kuo RL, Paterson RF, Lingeman JE. Simultaneous holmium laser enucleation of prostate and upper-tract endourologic stone procedures. $J$ Endourol. 2004;18(10):971-975.

49. Briganti A, Naspro R, Gallina A, et al. Impact on sexual function of holmium laser enucleation versus transurethral resection of the prostate: results of a prospective, 2-center, randomized trial. $J$ Urol. 2006;175(5):1817-1821.

50. Placer J, Salvador C, Planas J, et al. Effects of holmium laser enucleation of the prostate on sexual function. $J$ Endourol. 2015;29(3):332-339.

51. Elshal AM, Elmansy HM, Elkoushy MA, Elhilali MM. Male sexual function outcome after three laser prostate surgical techniques: a single center perspective. Urology. 2012;80(5):1098-1104.

52. Lourenco T, Shaw M, Fraser C, MacLennan G, N'Dow J, Pickard R. The clinical effectiveness of transurethral incision of the prostate: a systematic review of randomised controlled trials. World J Urol. 2010;28(1): 23-32.

53. Riehmann M, Knes JM, Heisey D, Madsen PO, Bruskewitz RC. Transurethral resection versus incision of the prostate: a randomized, prospective study. Urology. 1995;45(5):768-775.

54. Hellstrom P, Lukkarinen O, Kontturi M. Bladder neck incision or transurethral electroresection for the treatment of urinary obstruction caused by a small benign prostate? A randomized urodynamic study. Scand J Urol Nephrol. 1986;20(3):187-192.

55. Shore N, Freedman S, Gange S, et al. Prospective multi-center study elucidating patient experience after prostatic urethral lift. Can J Urol. 2014;21(1):7094-7101.

56. McNicholas TA, Woo HH, Chin PT, et al. Minimally invasive prostatic urethral lift: surgical technique and multinational experience. Eur Urol. 2013;64(2):292-299.

57. Roehrborn CG, Gange SN, Shore ND, et al. The prostatic urethral lift for the treatment of lower urinary tract symptoms associated with prostate enlargement due to benign prostatic hyperplasia: the L.I.F.T. study. J Urol. 2013;190(6):2161-2167.

58. Woo HH, Chin PT, McNicholas TA, et al. Safety and feasibility of the prostatic urethral lift: a novel, minimally invasive treatment for lower urinary tract symptoms (LUTS) secondary to benign prostatic hyperplasia (BPH). BJU Int. 2011;108(1):82-88.

59. Sonksen J, Barber NJ, Speakman MJ, et al. Prospective, randomized, multinational study of prostatic urethral lift versus transurethral resection of the prostate: 12-month results from the BPH6 study. Eur Urol. 2015;68(4):643-652.

60. Kim M, Song SH, Ku JH, Kim HJ, Paick JS. Pilot study of the clinical efficacy of ejaculatory hood sparing technique for ejaculation preservation in holmium laser enucleation of the prostate. Int J Impot Res. 2015; 27(1):20-24.

61. Alloussi SH, Lang C, Eichel R, Alloussi S. Ejaculation-preserving transurethral resection of prostate and bladder neck: short- and longterm results of a new innovative resection technique. J Endourol. 2014;28(1):84-89.

62. Leonardi R. Preliminary results on selective light vaporization with the side-firing $980 \mathrm{~nm}$ diode laser in benign prostatic hyperplasia: an ejaculation sparing technique. Prostate Cancer Prostatic Dis. 2009;12(3): 277-280.
Research and Reports in Urology

\section{Publish your work in this journal}

Research and Reports in Urology is an international, peer-reviewed, open access journal publishing original research, reports, editorials, reviews and commentaries on all aspects of adult and pediatric urology in the clinic and laboratory including the following topics: Pathology, pathophysiology of urological disease; Investigation and treatment of

\section{Dovepress}

urological disease; Pharmacology of drugs used for the treatment of urological disease. The manuscript management system is completely online and includes a very quick and fair peer-review system, which is all easy to use. Visit http://www.dovepress.com/testimonials.php to read real quotes from published authors. 